\title{
Focal Eosinophilic Myositis
}

\author{
Akio Kawabe ${ }^{1}$, Kazuhisa Nakano ${ }^{1}$, Aya Nawata ${ }^{1,2}$ and Yoshiya Tanaka ${ }^{1}$
}

Key words: focal eosinophilic myositis, eosinophilic myositis, eosinophils

(Intern Med 59: 141, 2020)

(DOI: 10.2169/internalmedicine.3602-19)
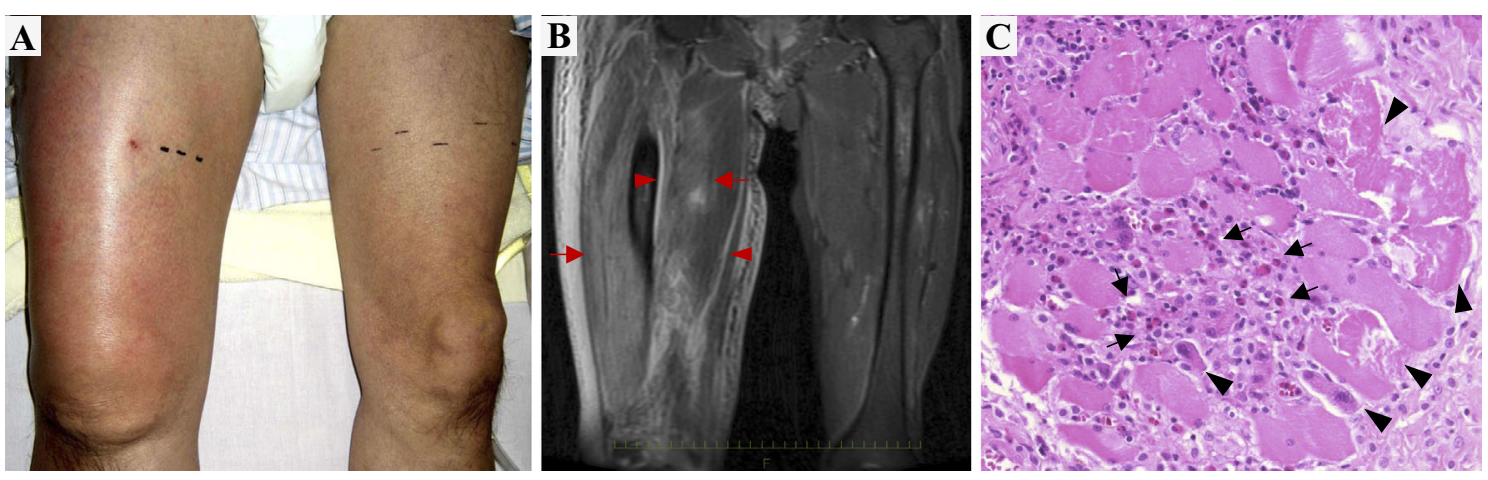

Picture.

A 72-year-old man presented to the hospital with a 2-day history of rapidly progressive, painful redness, swelling, and warmth of the right thigh (Picture A). His temperature was $38.9^{\circ} \mathrm{C}$; the creatine kinase level was $2,139 \mathrm{U} / \mathrm{L}$. Magnetic resonance imaging (Picture B) showed extensive hyperintensity in the muscle (arrows) and intermuscular fascia (arrowheads) on short-tau inversion recovery imaging. These findings suggested necrotizing fasciitis. However, a histological examination (Picture $\mathrm{C}$, Hematoxylin and Eosin staining) revealed endomysial mononuclear cell infiltration with eosinophils (arrows) and muscle fiber necrosis with regeneration (arrowheads). Subsequently, the eosinophil count increased to $2,223 / \mu \mathrm{L}$. The patient was diagnosed with focal eosinophilic myositis, a rare and self-limited disease with localized lower limb pain and swelling without other organ involvement (1). The thigh can also be affected $(1,2)$, but the etiologic factors were not identified in the patient. At one-month follow-up after the presentation, the symptoms had spontaneously resolved, with normal laboratory values shown.

The authors state that they have no Conflict of Interest (COI).

\section{References}

1. Selva-O'Callaghan A, Trallero-Araguás E, Grau JM. Eosinophilic myositis: an updated review. Autoimmun Rev 13: 375-378, 2014.

2. Kaufman LD, Kephart GM, Seidman RJ, et al. The spectrum of eosinophilic myositis. Clinical and immunopathogenic studies of three patients, and review of the literature. Arthritis Rheum 36: 1014-1024, 1993.

The Internal Medicine is an Open Access journal distributed under the Creative Commons Attribution-NonCommercial-NoDerivatives 4.0 International License. To view the details of this license, please visit (https://creativecommons.org/licenses/ by-nc-nd/4.0/).

\footnotetext{
${ }^{1}$ The First Department of Internal Medicine, School of Medicine, University of Occupational and Environmental Health, Japan and ${ }^{2}$ Department of Pathology, School of Medicine, University of Occupational and Environmental Health, Japan

Received: July 2, 2019; Accepted: July 8, 2019; Advance Publication by J-STAGE: August 21, 2019

Correspondence to Dr. Yoshiya Tanaka, tanaka@med.uoeh-u.ac.jp
}

(C) 2020 The Japanese Society of Internal Medicine. Intern Med 59: 141, 2020 